\title{
MEMÓRIAS, EDUCAÇÃO E AGROECOLOGIA: O PROCESSO DE FORMAÇÃO DOS MOVIMENTOS SOCIAIS DO SUL DA BAHIA - BRASIL
}

MARCELLA GOMEZ PEREIRA

Doutoranda em Memória: Linguagem e Sociedade (UESB). Mestre em Ecologia Humana e Gestão Socioambiental (UNEB). Licenciada em Ciências Biológicas (UESC). Membro do Grupo de pesquisa CORPORHIS - Corpo, História e Cultura. pereira.gomez@hotmail.com ORCID: https://orcid.org/0000-0002-2228-3481

FELIPE EDUARDO FERREIRA MARTA

Pós-doutor em Ciências da Saúde (Virginia Polytechnic Institute and State University). Mestre

e Doutor em História Social (PUC). Licenciado em Educação Física (UNESP). Professor pleno do Departamento de Ciências Naturais e docente no Programa de Pós-Graduação em Memória: Linguagem e Sociedade da Universidade Estadual do Sudoeste da Bahia. Docente do curso de licenciatura em Educação Física da Universidade Estadual de Santa Cruz. Líder do grupo de pesquisa CORPORHIS: Corpo, história e cultura. fefmarta@uesc.br ORCID: https://orcid.org/0000-0002-0501-4298

EDSON SILVA DE FARIAS

Pós-doutor em Ciências Humanas (Colégio do México). Doutor em Ciências Sociais (UNICAMP). Mestre em Sociologia (UNICAMP). Graduado em Comunicação Social (UFF). Professor adjunto do Departamento e do Programa de Pós-Graduação em Sociologia da Universidade de Brasília. Professor associado do Programa de Pós-Graduação em Memória:

Linguagem e Sociedade. Editor da revista arquivos CMD e Coordenador do Comitê de Sociologia da Cultura da Sociedade Brasileira de Sociologia. nilosed@gmail.com ORCID: https://orcid.org/0000-0002-9406-3269

RESUMO: Memórias permitem que indivíduos compartilhem experiências. A
agroecologia enquanto movimento de transformação, contribui na organização e
desenvolvimento de técnicas que garantem a estabilidade ecológica e a viabilidade
socioeconômica do processo produtivo. No Sul da Bahia, assentados da reforma
agrária utilizam memórias para adequar técnicas agroecológicas a seus repertórios
de conhecimentos, objetivando a melhoria da qualidade de vida de todos. Utilizando
a técnica História de Vida, este trabalho propõe-se a analisar as memórias sobre o
processo de ocupação de terra no Sul da Bahia, considerando os conflitos de terras, a
conservação dos sistemas naturais e a educação como ferramenta de transformação.

PALAVRAS-CHAVE: Campesinos, Memórias, Agroecológico, Nordeste, Brasil. 


\title{
MEMORIES, EDUCATION AND AGROECOLOGY: THE FORMATION PROCESS OF SOCIAL MOVEMENTS IN THE SOUTH OF BAHIA - BRAZIL
}

\begin{abstract}
Memories allow individuals to share experiences. Agroecology as a transformation movement, contributes to the organization and development of techniques that guarantee ecological stability and the socioeconomic viability of the production process. In the south of Bahia, agrarian reform settlers use memories to adapt agroecological techniques to their knowledge repertoires, aiming at improving everyone's quality of life. Using the History of Life technique, this work proposes to analyze the memories about the land occupation process in Southern Bahia, considering land conflicts, the conservation of natural systems and education as a transformation tool.
\end{abstract}

KEYWORDS: Peasants, Memories, Agroecological, Northeast, Brazil.

Recebido em: 08/07/2020

Aprovado em: 04/01/2021

DOI: http://dx.doi.org/10.23925/2176-2767.2021v70p288-313 
Não existe direito absoluto da propriedade da terra, a terra deve estar a serviço de toda a sociedade.

João Pedro Stédile

\section{Introdução}

Compilar informações acerca de conhecimentos tradicionais e locais, exige que cada indivíduo, em sua coletividade, acesse memórias ligadas ao processo de produção. Nesse sentido, tais memórias permitem que os indivíduos compartilhem aspectos positivos e também negativos, sobre técnicas de produção e manejo, sob a perspectiva de que a memória é uma operação dos acontecimentos e das interpretações do passado que se quer preservar (POLLAK, 1989).

No livro Memória Coletiva, Maurice Halbwachs apresenta um diálogo sobre como as lembranças podem estar organizadas em torno de uma determinada pessoa, assim como distribuídas dentro de uma sociedade, sendo ela grande ou pequena'. Nesse sentido, as memórias dos movimentos sociais em torno de sua trajetória de lutas por terras, são a construção política e social de cada sujeito junto ao grupo a que pertencem e que representam.

Grupos organizados a partir de um ideal político e social de luta pela terra, tal qual movimentos sociais e associações de trabalhadoras e trabalhadores rurais, contribuem sobremaneira para o planejamento, a organização e a implementação de ações voltadas ao desenvolvimento da agroecologia como meio para ampliar o acesso e promover a melhoria da qualidade dos alimentos, assim como garantir a segurança alimentar e nutricional de produtores e consumidores (CANAVESI, MOURA, SOUZA, 2016).

Como ciência integradora do conhecimento técnico moderno e tradicional, a agroecologia busca a construção de alternativas, de acordo com cada localidade; o que permite enfatizar a heterogeneidade cultural, política e territorial no planejamento participativo de cada local (BORGES, 2010). Nessa perspectiva, a agroecologia pode ser conceituada como o manejo ecológico

\footnotetext{
' Olga Yanet A. Rodríguez. El Pasado: Historia o Memoria. Historia y Memoria, 2014, p.63.
} 
dos recursos naturais, por meio de formas de ação social coletiva (SEVILLAGUZMÁN, 2009).

Movimentos sociais e associações de trabalhadores rurais construíram um caminho de luta para a terra cumprir seu papel social (ZACCHI, 2016); da mesma forma, têm investido em conhecimento técnico e em estratégia de natureza sistêmica, para potencializar o valor endógeno de conhecimento local, seja ele quilombola, camponês e/ou indígena, como meio para conservar a biodiversidade ecológica e sociocultural de cada lugar e grupo social.

A importância do contexto social, político, cultural e ambiental que representa o Sul da Bahia pode ser lido em muitas obras de memorialistas regionais, tal como Adonias Filho, e também nos textos do escritor Jorge Amado, os quais, no entanto, representam apenas uma porção do histórico que envolve essa região². Objeto de cobiça, devido ao seu grande potencial na produção cacaueira ${ }^{3}$, o Sul da Bahia foi local de conflitos e atualmente é local de resistência ${ }^{4}$.

Nesse sentido, o referido trabalho objetivou analisar, a partir das memórias de participantes do Movimento dos Trabalhadores Rurais Sem Terra (MST) e de uma associação de trabalhadores rurais, o processo das primeiras ocupações e organização dos movimentos sociais no Sul da Bahia, assim como dos conflitos gerados devido às ocupações de terra e sobre a mudança do modo de produção convencional para o agroecológico, que, além de um sistema de produção, é um modelo de engajamento político e educacional.

A seguir, detalham-se o aparato metodológico utilizado para desenvolver o trabalho de pesquisa, o material narrativo passível de organização, através de entrevistas e considerações acerca do que foi discutido durante o desenvolvimento deste trabalho. Utilizou-se um método

\footnotetext{
${ }^{2}$ A "Vila de São Jorge dos ilheos" foi fundada em 1536.

3 A região Sul da Bahia tornou-se uma grande exportadora de amêndoas de cacau entre as décadas de 1970 e 1980, o que gerou aumento do potencial econômico local. Devido ao rápido enriquecimento, muitos proprietários de terras se valiam de suas riquezas para "tomar" propriedades menores e expandir suas plantações.

${ }^{4}$ A ausência de políticas públicas adequadas, a permanência de processos sobre a reintegração de posse de algumas áreas e as divergências políticas causadas por partidos que se aproveitam da fragilidade social e econômica de alguns assentamentos, implica na resistência que os movimentos sociais têm que empregar, a fim de permanecerem exercendo o trabalho na terra, e (re) afirmando a função social de tal recurso.
} 
de aproximação junto aos colaboradores, em que as entrevistas sobre o processo de ocupação de terras no Sul da Bahia tiveram como objetivo, investigar os eventos que estavam apenas em suas memórias individuais, e, assim, conduzir o leitor a uma compreensão sobre esses eventos, a partir de diferentes espaços e temporalidades.

Em outras palavras, as narrativas a que o estudo teve acesso representam versões exclusivas do processo de ocupação, muitas vezes conflituoso daquelas terras. São detalhes a respeito de eventos, que não figuram nos documentos oficiais, daí a sua relevância para a memória e para a história da Bahia e, por consequência, do Brasil.

\section{História Oral: reflexões metodológicas}

O ponto de partida para o desenvolvimento da pesquisa qualitativa, que tange uma abordagem interdisciplinar, foi a seleção da história de vida como técnica de compreensão biográfica da formação dos grupos e movimentos sociais de luta pela terra no Sul da Bahia. Sendo a narrativa uma perspectiva teórico-metodológica relevante a investigação social, consideramos as fontes orais como narrativas que contam com a particularidade da subjetividade do narrador, as quais referenciam-se tanto aos significados como aos acontecimentos 5 .

Para Josso (1999) os procedimentos de história de vida, tal como foram desenvolvidos ao longo dos anos, articulam-se a dois tipos de objetivos teóricos: a um projeto de deslocamento do posicionamento do pesquisador, mediante refinamento de metodologias de pesquisa formação articuladas à construção de uma história de vida; e ao conhecimento sobre essa metodologia, que tem contribuído para a delimitação de novos territórios e para a reflexão sobre formação e auto formação de um público em particular. Consideramos a abordagem reflexiva de auto formação, já que utilizando as memórias de sujeitos engajado na luta experiencial e coletiva por terra, construímos um perfil intelectual sobre uma abordagem biográfica.

\footnotetext{
${ }^{5}$ Melina Jean Jea. La Historia Oral y la narrativa como metodologías para el abordaje del terrorismo de Estado, siglo XX en Argentina. Historia y Memoria, 2020, p.71
} 
A partir de entrevistas individuais, o trabalho teve por objetivo analisar o processo de organização, desenvolvimento e manutenção dos movimentos sociais no Sul da Bahia. O processo de colaboração dos narradores ocorreu após aprovação do projeto de pesquisa "Memórias Bioculturais: a influência dos movimentos sociais na conservação da biodiversidade, etnodiversidade e agrodiversidade da Mata Atlântica, Bahia, Brasil" em conformidade com as normas éticas exigidas para realizar pesquisas com seres humanos no Brasil.

Para as entrevistas, utilizou-se gravador de voz e nenhum registro fotográfico, tendo em vista a manutenção do sigilo das identidades dos colaboradores, exigência cumprida de acordo com o Termo de Consentimento Livre e Esclarecido (TCLE) aprovado. Os nomes utilizados no decorrer do artigo são fictícios. São nomes de árvores que compõem a biodiversidade da Mata Atlântica baiana. Cada nome escolhido está acompanhado pelo respectivo nome científico da espécie.

Cada colaborador da pesquisa narrou suas memórias acerca da organização dos movimentos sociais no Sul da Bahia, dos conflitos gerados pela ocupação de terras e sobre a construção de um novo modelo de produção - as necessidades de organizar esse novo modelo, as dificuldades que enfrentaram e enfrentam para otimizar, ampliar e multiplicar a ideia de uma produção socialmente justa, economicamente viável e ambientalmente correta - e a importância da transformação para que os jovens tenham melhores chances de crescimento pessoal e uma qualidade de vida digna.

As informações obtidas durante a realização das entrevistas, foram confrontadas com um referencial bibliográfico específico. Este processo, terá por finalidade contribuir para a apresentação de fatos sobre a organização dos movimentos sociais no Sul da Bahia, dos conflitos em torno da ocupação de terras nesse território e para o debate em torno dos prós e contras do sistema de produção agroecológico.

Os depoimentos abaixo relatam múltiplas experiências: convivências dos grupos em meio às lutas por terra, desenvolvimento de técnicas de produção mais ecológica, a perda de companheiros e companheiras durante a trajetória dessas lutas. As memórias a seguir promovem o entendimento sobre a importância do processo de transição da produção convencional para a agroecológica (termo inserido na pesquisa através de questionamentos durante as entrevistas), como mecanismo de educação e engajamento 
político, assim como expõem os temores sobre a ausência de políticas públicas eficientes para salvaguardar o conhecimento ancestral, o conhecimento adquirido e as inovações empregadas na conservação dos sistemas de produção.

\section{Memórias dos colaboradores}

\subsection{As primeiras ocupações de terras no Sul da Bahia}

As lutas dos movimentos sociais no Sul da Bahia vão além da conquista por um lote de terra agricultável; simbolizam a reestruturação de uma parcela da sociedade que vendia sua força de trabalho aos cacauicutores, que foi silenciada por ser testemunha das mazelas que atingiram a região Sul da Bahia e que representa o sofrimento dos trabalhadores rurais, que tiveram terras usurpadas. Nesse sentido, as memórias dos colaboradores permitem a descrição do que já foi contado, porém por uma perspectiva diferente, ou seja:

[...] a memória não é o oposto de esquecimento. Ela é resultado da interação entre esquecimento e lembrança. De todos os sinais deixados pelo passado, apenas alguns são escolhidos para serem perpetuados. Uma vez estabelecidos os fatos, é preciso interpretá-los, relacioná-los uns aos outros, reconhecer causas e efeitos, formular semelhanças e gradações, oposições (PAIXÃO e FRISSO, 2016).

Para Portelli (1998), a elaboração da memória e o ato de lembrar são sempre individuais, pois são as pessoas que se lembram e não os grupos. Desse modo, cada indivíduo extrai memórias de uma variedade de grupos e as organiza de forma idiossincrática. As memórias sobre as primeiras ocupações no Sul da Bahia são as perspectivas detidas, por cada entrevistado, sobre os eventos, e, assim, podem ser complementares, opostas ou colaborativas, mas representam de fato uma verdade sobre esse período.

Cedro (Cedrela odorata) é uma das lideranças do Movimento dos Trabalhadores Rurais Sem Terra da Bahia (MST-BA), que experienciou, enquanto jovem, a organização e a militância do MST. Atualmente não exerce cargo de liderança, mas acompanha as atividades do movimento, como conselheiro. Sobre o MST na região sul baiana, ele relata: 
No final da década de oitenta surgiu o MST, que veio pra cá (Sul da Bahia - grifo nosso) por conta da crise cacaueira, fazendas abandonadas, seca - tinha dado uma seca imensa e por isso o cacau foi lá pra baixo, muitos fazendeiros não moravam aqui e abandonaram mesmo. O MST chega na região e organiza as ocupações de terras, pra poder ter êxito em relação a reforma agrária intensifica a luta. Veio do extremo sul para o sul, a segunda região em que o MST se organizou na Bahia foi o Sul da Bahia, e aí algumas lideranças do Extremo Sul vieram para o Sul pra fazer essa ação como movimento social organizado, tem Joelson, Vera Lúcia, Valmir, Fábio que morreu. Organizou a luta dos trabalhadores como movimento social organizado, teve uma ocupação em Arataca na fazenda Bela Vista, que hoje é assentamento Terra Vista. Uma resistência, que aí conseguiu desapropriar a primeira área no Sul da Bahia, a primeira aqui no Sul é a Terra Vista (Cedro. Marcella Gomez. 09/2019).

Durante a entrevista, Cedro narrou a luta, em seus aspectos violentos: morte de companheiros, chacinas de posseiros e pistoleiros pagos para "dar cabo" de pequenos proprietários de terras. Suas experiências promoveram o desenvolvimento de suas concepções sobre coletividade, que ele disponibiliza a seus companheiros de luta durante o processo de formação das novas lideranças. Dessa maneira, a memória pode se tornar uma arma política, ela não obedece apenas à razão, mas às tradições herdadas e a sentimentos profundos (ARAÚJO e SANTOS, 2007).

No ensaio sobre o massacre de Civitella, Val di Chiana, Portelli (1998) descreve como as memórias são capazes de expressar raiva e violência, no entanto, analisa que não se devem considerar essas memórias um núcleo sólido, impenetrável ao pensamento, imune à história ou à política e inacessível à análise crítica. Desse modo, considera-se que as memórias são capazes de construir a essência de uma mesma experiência antropológica, de modo a formalizar, em narrativas, as atividades humanas que contribuem para a construção de uma história social.

Outro colaborador desse trabalho narra suas memórias sobre o processo de ocupação de terra no Sul da Bahia pelos movimentos sociais e a importância do cooperativismo no sucesso desse processo. Samuma (Sterculia excelsa) foi uma das lideranças nacionais do MST. Suas memórias narram o processo de construção dos movimentos sociais na Bahia desde as primeiras ocupações do extremo Sul:

O MST nasceu no extremo Sul da Bahia, o MST da Bahia em 1987, no assentamento, a primeira ocupação foi o projeto $40 \times 45$ e no mesmo ano em dezembro, isso foi em setembro, 7 de setembro o $40 \times 45$, e o 
segundo acampamento da Bahia foi em dezembro de 1987, Riacho das Ostras. A terceira ocupação que foi a que eu participei, que foi em março de 1988, na fazenda Bela Vista em Itamaraju, Bahia. Depois de três meses de ocupação nos fomos despejados e em julho nois faz uma ação no extremo sul extraordinária, que ocupa 10 fazendas em espaço de 3-4 dias, a mais emblemática foi a fazenda Corumbau no município do Prado, e depois uma fazenda na Brasiolanda, município de Porto Seguro. Essas são as principais ocupações do extremo Sul, a mais emblemática foi a Corumbau, que a gente inclusive ganhamos prêmios de resistência [...] prêmio nacional de melhor resistência de massa e de grupo (Samuma. Marcella Gomez. 10/2019).

Samuma narra suas memórias sobre o processo de concepção e da construção do MST na Bahia, primeiro movimento social organizado na região, e enaltece as conquistas realizadas por ele e seus companheiros de luta, isso porque, a região que pertencia aos poderosos cacauicutores havia sido tomada para cumprir sua função social, e teve reconhecimento nacional por isso. Dessa maneira, é necessário reconhecer que sistemas sociais que concentram seus esforços em organizar uma rede de cooperação e assistência estão decididos a implementar estratégias para promover a dignidade humana a partir da distribuição equitativa de recursos (terra, água, sementes) (LUNA e AGUILAR, 2015).

De acordo com Labaut, a memória surge como um meio para que a narrativa opere, mas essa mesma memória, motor da narrativa, é apenas um passo em direção a um deslocamento do olhar que nos arranca do passado e nos projeta para uma abertura que deixa entrever o presente-futuro (LOPES, 2014). Nessa perspectiva, o uso da técnica história de vida surgiu como a mais apropriada aos objetivos do trabalho, tendo em vista que, a partir dela, é possível acessar memórias utilizadas como ferramenta de crescimento pessoal e coletivo, as quais são utilizadas no processo de ensino/aprendizagem dos movimentos sociais.

Diferente de Cedro e Samuma, que narraram suas participações na construção da luta por terras na região Sul da Bahia, a partir do final dos anos de 1980, Ipê-roxo (Tabebuia heptaphylla) participou ativamente da luta por terras na mesma região desde o início de 1970. As memórias de Ipê-roxo relatam a organização, as estratégias e a consolidação dos movimentos sociais, na mesma região, mas em uma diferente perspectiva de espaços e tempo: 
A luta pela terra no Sul da Bahia começou na década de 1970 [...] primeiro teve toda essa questão da situação da cacauicultura, que a vassoura de bruxa dizimou a região, isso intensificou mais ainda a questão das ocupações. Lembro que uma vez em Canavieiras a gente juntou mais de 300 grupos de luta pela terra, e naquele momento era questão de tudo ou nada, a gente não tinha nenhuma interlocução, a gente tinha naquele período bravo, assim dizer, a gente tinha o apoio da CESI (Coordenadoria Ecumênica de Serviço), naquele tempo difícil, eles apoiavam, denunciavam, então era um apoio. Mesmo a gente na $\mathrm{CPT}$, que era da igreja, a igreja não apoiava assim, porque quem era da igreja? Os fazendeiros, coronéis. Lembro que uma vez eu estava vindo com uma companheira do campo e o padre que era coordenador da CPT, mas que também tinha fazenda (pausa), a questão aqui era tão complicada que tinha padroeira que tinha fazenda, aí ele deu carona pra gente, aí apresentou ao outro que também era fazendeiro, aí ele disse assim: "olhe essas são as meninas que fazem o trabalho contra nós". E aí chegou a um ponto que a questão ficou tão intensa, e a igreja é claro tinha o limite dela, naquele tempo então que os companheiros começaram a me pressionar, porque assim, a igreja só vai até aqui então você também só vai até aqui na luta com a gente, entendeu. Então eu tive que fazer a opção de dizer: "agora eu tenho que abrir mão desse guarda-chuva que é a igreja", a CPT, e cai na luta mesmo, cai no mundo mais ainda né (Ipê-roxo. Marcella Gomez. 09/2019).

Devido à crítica situação de luta por terras e da escravização da mão-deobra de trabalhadores rurais em todo o Brasil, a Igreja Católica, com o compromisso de assistir as famílias envolvidas, fundou durante o Encontro de Bispos e Prelados da Amazônia, convocado pela Conferência Nacional dos Bispos do Brasil (CNBB), a Comissão Pastoral da Terra (CPT) em junho de 1975. Na região Sul da Bahia, a CPT desenvolveu trabalhos de fortalecimento da cultura camponesa; no entanto, a posse de terras por alguns dos representantes da Igreja representou um conflito de interesses, o que levou à limitação das atividades da instituição na região.

A colaboração de Ipê-roxo, atualmente membro assentado da reforma agrária, na construção da Comissão Pastoral da Terra (CPT) no Sul da Bahia, representou a perpetuação de seus ideais sobre a importância da luta por terras. Sua luta por igualdade de direitos, que teve início durante sua juventude, se intensificou conforme seu envolvimento nos movimentos sociais e promoveu seu desenvolvimento pessoal:

Nessa luta eu tive três batismos né, uma que é a questão do movimento sindical de ver a miséria no meio de tanta riqueza dos fazendeiros de cacau, mas a miséria dos trabalhadores e trabalhadoras rurais né, que a gente dizia que era uma morte, mas que não se dava muita importância porque não tinha o sangue. Era uma morte sem sangue, então isso não causava indignação nem nada, e quando a gente 
começou essa luta da tomada dos sindicatos foi um horror (...) aí teve a questão da luta pela terra, que aí foi sangue mesmo, porque a situação aqui na região teve um período, embora no país inteiro aquela região do Araguaia era mais violente né, no ponto de vista, mas teve um momento que a gente tava pior que aquela região do Pará. Aqui na região tinha sindicato do crime organizado (...). Meu terceiro batismo foi a questão das mulheres, a luta das mulheres, que embora as mulheres sempre estiveram presentes na luta, mas era a questão da invisibilidade ${ }^{6}$, da desvalorização, então esse foi meu terceiro batismo, de lutar, dá luz a luta das trabalhadoras rurais. Todas eram uma luta só (Ipê-roxo. Marcella Gomez. 09/2019).

Para Ipê-roxo, a luta por terras não foi emancipatória por determinar seu lugar como militante, mas pelo fato de, a partir desta luta, (re) nascer para si e para os outros como militante, educadora e mulher. Ao ressignificar as etapas de desenvolvimento pessoal que atravessou, ela referiu-se ao batismo, primeiro sacramento da Igreja Cristã, que representa a purificação do indivíduo através da água. Nesse contexto, a cada novo "batismo", Ipê-roxo tornava-se purificada e pronta para receber um novo sacramento; nesse caso, uma nova percepção sobre as mazelas sociais que a luta por terras carregava.

Nossa colaboradora enfrentou momentos de angústia, de medo e de perdas. Em suas memórias estão as perdas de muitos companheiros de luta, mas ela narra que os cuidados entre eles mantiveram outros tantos vivos. 0 percurso da luta por terras no Sul da Bahia não foi fácil, mas manteve-se pela força de seus líderes. A persistência de uns fez e permanece fazendo diferença no status de transformação política, social e cultural desses grupos. Ipê-roxo acredita que, para consolidar tais mudanças, se faz necessário respeito ao ambiente:

A questão ambiental é opção de vida, porque assim, mesmo tendo tido toda essa formação política, marxista, sei lá o que tá tá, à medida que eu me entranhei na questão ambiental eu descobri que a questão ambiental é o que existe de mais revolucionário, porque ela questiona, lembra aqueles pontos de que o que você vai fazer, pra que vai fazer, como você vai fazer, pra quem você vai fazer, então você questiona tudo dentro desse contexto, então assim, a gente começou a pensar que, ou você trabalha pensando na preservação ou você tá fadado a tá fazendo uma produção em decadência, vamos assim dizer, porque cada vez você deteriora sua terra e tudo isso significa que você tem que aumentar essas coisas todas, e sem falar que a cada dia você tem que ir derrubando mais e também do ponto de vista, eu acho pelo menos

\footnotetext{
${ }^{6}$ Sobre a invisibilidade da mulher em espaços de luta, Portelli (2010) faz uma análise acerca das mulheres de mineradores nos EUA que, em 1930 ocuparam frentes de serviço na ausência de seus maridos, mas que não desenvolviam habilidades de leitura e escrita devido à baixa autoestima e opressão de companheiros. Ver página 106 a 109.
} 
na minha convicção, é que toda a degradação do ser humano tá ligada a questão da degradação ambiental [...] Nos acampamentos já era um trabalho preventivo, então você fazia todo o trabalho de educação ambiental, já pra quando eles irem para as fazendas eles irem com outra visão de preservação (Ipê-roxo. Marcella Gomez. 09/2019).

A importância do ambiente na organização social não é um elemento de menor relevância no que tange ao bem-estar de nossos colaboradores. Essa constatação, aproxima este estudo do trabalho realizado por Portelli (2010), onde o autor apresenta a narrativa de Annie Napier, residente dos Apalaches nos EUA, sobre a destruição e a contaminação da terra por mineradoras e madeireiras; essa narrativa incentiva a crítica como papel social:

Ninguém respeita mais a terra. E se você não a respeita, ela se rebela contra você. Te faz pagar um preço, entende? E o problema é que quem sofre com as consequências são os pobres, aqueles que não podem se defender sozinhos (PORTELLI, 2010, p.98).

Segundo Leonardo Boff, "sabemos por um dado empírico da ciência, que somos irmãos e irmãs responsáveis uns pelos outros e interdependentes de tal maneira que, essa interdependência faz com que a cooperação seja a lei mais suprema do universo"7. No entanto, essa é mais uma das leis que são desrespeitadas diariamente, tendo em vista que, na maioria das vezes, não se pensa de modo cooperativo.

Outra colaboradora a ser apresentada nestas páginas representou, e ainda representa, um enorme ganho à luta por terras no Sul da Bahia. Jequitibá-rosa (Cariniana legalis) é original de São Paulo, mas tornou-se assentada nos anos 2000. Passou pela decisão do conselho do assentamento a que se uniu para receber o direito a um lote de terra. Tendo em vista que seus descendentes não tinham histórico de luta pela terra, foram questionadas pela pesquisa suas motivações para engajar-se nesse desafio. Ela explicou:

Só eu vim, meu esposo ficou meio assustado, foi na época que o assentamento aqui estava saindo, porque não vim direto pra esse, vim pra um próximo. Quando houve a reintegração de posse, saiu aquela notícia, muita polícia, o pessoal saindo, aí bate aquela situação de você achar que não vai dar certo, vai ser uma perda de tempo. Falei a ele que

\footnotetext{
${ }^{7}$ Palestra de abertura proferida por Leonardo Boff no VIII Congresso Brasileiro de Agroecologia, realizado entre os dias 25 a 28 de novembro de 2013 em Porto Alegre, Rio Grande do Sul, transcrita por Junior Miranda Scheuer e publicada pela revista NERA em 2016.
} 
ele não ia, mas eu ia. A luta tá no meu seu sangue, pois mesmo não participando de movimentos sociais eu tinha curiosidade em ver, em conhecer e saber como era. Mesmo sofrendo discriminações por ser mulher, não desisti da luta pelos meus direitos. Lembro que no primeiro assentamento conseguiu lugar junto a direção do assentamento ao conseguir um caminhão de cestas básicas, e mesmo assim não tinha espaço (Jequitibá-rosa. Marcella Gomez. 10/2019).

Jequitibá-rosa é neta de agricultores, suas memórias narram as experiências que ela adquiriu do processo de trabalho de seus avós. A "luta está no meu sangue", é uma frase que reverbera o compromisso social que ela admitiu ter com seus semelhantes. Nesse sentido, é possível referir-se à memória como a coesão dos grupos que compõem uma sociedade, e como elemento que estabelece as posições em relação uns aos outros no complexo processo de registro das recordações passadas (RIBEIRO, 2005).

Para os movimentos sociais, o importante é que a terra pertença a quem de fato trabalha nela, combatendo a desigualdade social, promovendo o desenvolvimento sustentável e otimizando a proteção ao ambiente (ZACCHI, 2016). Nossos colaboradores expressaram, em suas narrativas, o valor do trabalho na terra, a importância da conservação para o fortalecimento do movimento e a necessidade de legitimar o contexto político, social, econômico e ambiental que defendem. Através da agroecologia como matriz tecnológica de produção e da valorização do conhecimento camponês, os movimentos sociais vêm redefinindo suas estratégias de organização voltadas para as localidades (BORGES, 2010).

\subsection{Educação Agroecológica: transformação e empoderamento}

As memórias podem ser vulneráveis, mas representam um patrimônio imaterial que contribui a unir os membros de um grupo, permitindo-Ihes se situar no passado, no presente e no futuro (FRANÇOIS, 2010). Trabalhar o olhar técnico e científico para reconhecer a importância do conhecimento tradicional sobre os meios de produção não só estimulam o setor produtivo, mas o social e o ambiental, à medida que as memórias são relacionadas à revalorização do componente humano.

No contexto de desenvolvimento deste trabalho, a agroecologia surge como uma ferramenta de apoio a um novo (re) começo, pois a produção se 
estrutura em torno do ritmo da natureza. No entanto, se faz necessário compreender que a agroecologia é um sistema de produção que visa a educar para a sociedade, conservar para a humanidade e produzir para assegurar alimentos de qualidade. Sevilla-Guzmán (2002) afirma que:

A agroecologia se propõe não só a modificar a parcelização disciplinar, senão também a epistemologia da ciência, ao trabalhar mediante a orquestração de distintas disciplinas e 'formas de conhecimento' que compõem seu pluralismo dual: metodológico e epistemológico, onde a perspectiva sociológica tem um papel central.

Leff (2002) reafirma a importância do conhecimento camponês para a construção da agroecologia, e defende que as práticas agroecológicas remetem à recuperação de saberes tradicionais, a um passado no qual o ser humano era dono do seu saber, a um tempo em que seu saber marcava um lugar no mundo e um sentido de existência. A narrativa de nossos colaboradores acerca da agroecologia como resultado da transformação sociocultural dos assentamentos, proporcionou um entendimento sobre a importância da valorização do conhecimento tradicional camponês no desenvolvimento social e político de cada um.

Para Ipê-roxo a militância vai além dos deveres sociais e políticos. São também educacionais; logo, além da preparação para a luta por terras, a educação é a base para a organização de um conjunto forte, empoderado e capaz de manter ações desenvolvimentistas ancoradas nos ideais de igualdade, inclusão e oportunidade. No trecho a seguir, vê-se a preocupação com o "educar para manter a luta", com a posição das mulheres nessas organizações sociais e com a importância do trabalho feminino:

Víamos a educação como prevenção, isso porque quem tava acampado já tinha sua produção por ali e então a gente fazia toda essa orientação, toda essa discussão com quem fosse, com as mulheres e tal, porque pra mim as mulheres são as guardiãs da vida, e assim a consciência, o conhecimento que elas tem desse aspecto ambiental é uma coisa extraordinária porque, acredito assim, como elas foram impedidas de falar durante muito tempo, aguçou a questão da observação, então isso fez delas pesquisadoras fantásticas. Por um lado, destruídas como ser humano, que não era diferente dos companheiros, mas pras mulheres tem todos os outros agravantes né, da violência sexual, todas as violências; trabalhar e ver essas figuras desabrochando uau, é uma coisa fantástica. Sempre fui preocupada com as questões ambientais e vi os resultados, porque acredito que quanto mais há degradação, quem mais é penalizado são as mulheres, porque assim, vamos supor, tem que fazer o fogo de lenha, se tá tudo destruído tem que andar 
quilômetros pra ir. Quem vai buscar água não sei aonde, são as mulheres, e aí, pra mim, por essa questão da degradação a questão da violência aumenta, porque se é uma produção em decadência, todo o clima tá acirrado mesmo em família, o homem, e aí pra mim cria uma cadeia, o homem que espanca a mulher, que espanca o filho, que espanca os animais, então cria uma cadeia de violência, embora não percebam que isso, que todas as coisas estão ligadas a questão da degradação ambiental, essa questão da sua degradação como pessoa humana. Tem que trabalhar a família (Ipê-roxo. Marcella Gomez. 09/2019).

Caldart e colaboradores (2013) apontam a presença de escolas dentro dos movimentos sociais antes mesmo de suas organizações formais chegarem com suas bandeiras. De acordo com os autores, a organização do Setor da Educação do Movimento vai além da conquista de escolas para as áreas de reforma agrária, buscando uma relação de coerência entre o Projeto Político Pedagógico das escolas, as necessidades dos sujeitos do campo e os objetivos estratégicos de organização coletiva ao qual estão vinculados.

Para Jequitibá-rosa, a educação também representa o alicerce mais tenaz sobre o qual os movimentos sociais ganham força, respeito e credibilidade. Seu sucesso na organização do assentamento significou a conquista de cestas básicas entregues às famílias assentadas, a fundação de uma escola dentro da área do assentamento e a admissão de um educador assentado para atuar na escola. Mesmo antes de representar seus companheiros de luta como presidente da associação, Jequitibá-rosa considerava inadmissível a situação de analfabetismo dentro do movimento, e, junto à prefeitura municipal, conquistou o aparto educacional necessário para alfabetizar os assentados:

A prefeitura atendeu nosso pedido, uma das coisas que eu exigi é que fosse professor da comunidade, porque eu acho que seria um incentivo, e eles passarem a dar credibilidade também. Eles colocaram um professor daqui na época, e a prefeitura exigiu que eu apresentasse a lista de alunos. A gente saiu por aí colocando, e pra que pudesse ter uma credibilidade maior eu falei não, vou colocar meus filhos também (Jequitibá-rosa. Marcella Gomez. 11/2019).

A educação formal dentro do assentamento transformou a realidade de cada indivíduo, mas também da coletividade. As assinaturas por impressão digital deixaram de ser predominantes, houve compreensão sobre as exigências de demarcação de Reserva Legal e Área de Preservação 
Permanente, para atender a política ambientalista brasileira, que por sua vez foram empreendidas e tornaram-se responsabilidade de todos. Segundo Jequitibá-rosa, todas essas transformações foram possíveis a partir da educação formal realizada pela escola local e da educação para a conservação a que tiveram acesso:

O Jupará8 quando veio, veio como ONG de preservação. Eles vieram e começaram a ensinar ao pessoal todas as técnicas de conservação, de não usar produtos químicos, de fazer as caldas biológicas, como tratar a situação de cacau, fazer as barreiras de contenção, as curvas de nivelação, então assim, todo o trabalho ambiental o Jupará passou (Jequitibá-rosa. Marcella Gomez. 11/2019).

A alfabetização dos assentados proporcionou uma adesão ao código florestal, isso porque, além da obrigatoriedade de estabelecer as Áreas de Preservação Permanente ${ }^{9}$ e Reservas Legais ${ }^{10}$ (ambas normatizadas pela Lei 12.651/2012) devido às questões fundiárias dos assentamentos, ao cumprir a legislação, todos os participantes do assentamento seriam beneficiados, fosse através de créditos financeiros, disponibilizados por instituições bancárias públicas ou de autarquia mista, para empregar no desenvolvimento de suas áreas de produção; fosse na manutenção dos recursos alimentícios que a conservação das áreas florestais proporcionavam.

A manutenção de áreas protegidas se mostra um fator essencial para garantir a conservação da biodiversidade (PRIMACK e RODRIGUES, 2001), a redução das pressões ambientais e assegurar a importância do contexto espacial sobre os processos ecológicos no caráter fundamental das interações (MAYWALD e JÚNIOR, 2012). Manter o bom funcionamento dos assentamentos em meio a disputas, foi possível com a organização de espaços para formação dos sujeitos. Compreender a dinâmica ecológica acerca do processo de produção foi proporcionado através da escolarização, e o compromisso com a conservação do espaço que os abriga, pôde ser

\footnotetext{
${ }^{8}$ A Fundação Jupará presta serviços à arte e a cultura do Sul da Bahia e luta pela ecologia através da educação.

9 Florestas e demais formas de vegetação natural situadas às margens de lagos ou rios; nos altos de morros; nas restingas e manguezais; nas encostas com declividade acentuada e nas bordas de tabuleiros ou chapadas com inclinação maior que 45; e nas áreas em altitude superior a 1.800 metros, com qualquer cobertura vegetal.

10 Área do imóvel rural que deve ser coberta por vegetação natural e que pode ser explorada com o manejo florestal sustentável. Ela varia de acordo com o bioma em que está a propriedade.
} 
alcançado com a inclusão dos assentados no sistema de alfabetização e escolarização.

$\mathrm{Na}$ narrativa de Cedro, o processo de educação promoveu o fortalecimento do movimento e o compromisso com os ideais defendidos tornou-se maior, o que conduziu o movimento a uma reestruturação quanto ao modo de produção. Entre mudanças e comprometimentos, o MST na região Sul da Bahia iniciou um trabalho de educação e fortalecimento sobre a importância da agroecologia como ferramenta para o manejo de recursos naturais em direção à subsistência dos seres humanos.

Existe uma mudança, tanto existe que já tem vários assentamentos com a agricultura orgânica, fazendo e discutindo agroecologia o tempo todo. Várias escolas de assentamentos com os cursos voltados pra questão da agroecologia, no Terra Vista tem o curso em técnico em agroecologia, tem as especializações dos cursos superiores também com a agroecologia, vários cursos de formação de agroecologia, viveiros produzindo mudas agroecológicas, área de cacau já com a produção agroecológica, orgânica, inclusive com certificação pra conseguir vender num preço melhor, com mais renda. Então há uma mudança muito grande em relação a isso (conservação) (Cedro. Marcella Gomez. 09/2019).

Algo que chama a atenção nas narrativas é a relação da educação dentro dos movimentos sociais e a adesão à produção agroecológica. Construir um processo educacional diferenciado, autônomo e holístico é essencial ao bom desempenho dos movimentos sociais em relação a sua construção e desenvolvimento político, social e cultural. Para Wigg et al. (2016), pensar agroecologia é enunciar as contradições socioeconômicas do modelo convencional de reforma agrária vinculado a uma agenda de interesses econômicos.

O uso do termo agroecologia representa, nesse contexto de narrativas, uma ferramenta fundamental na construção, na transformação e na mediação de conhecimentos, ideologias e ações, que tem auxiliado gerações na tomada de decisões e no empoderamento crítico sobre o que é bom e o que não é bom para si e para o coletivo.

As memórias de Samuma, como assentado responsável pela organização, desenvolvimento e execução de ações acerca da comercialização, institucionalização e expansão das atividades do MST no Sul da Bahia, ligadas ao desenvolvimento agroindustrial de alguns 
assentamentos, narram o processo de ocupação e apresentam a importância de educar para a luta por terras como meio para alcançar a dignidade social:

Nós estamos tentando ir para além da cerca e nesse sentido nós, a primeira coisa foi a discussão "a terra tem que ser medida pelo trabalho". Cada agricultor tem aquilo que ele trabalha, que ele cultiva, e nois evoluiu, tem uns cinco anos que nois tá evoluindo, que tá nessa discussão de para além da cerca, elegemos, são quatro prioridades que temos que eleger pra isso: primeiro é a conquista da terra; segundo a conquista da soberania alimentar, ou seja, da existência; terceiro a renda e quarto a educação, que aí é o maior problema, porque essa educação tem que ser para além do capital. Como dependemos do Estado, o Estado dá a educação da normalidade, a educação escravista, escravocrata, então também é um problema, então essas três premissas, essas quatro premissas são fundamentais para o sucesso dos sem-terra. Nós optamos por ter nossa própria escola, mais nós estamos com um problema gravíssimo, que a escola vem de fora pra dentro (Samuma. Marcella Gomez. 10/2019).

Ao se pensar sobre o processo de desenvolvimento em etapas, Samuma revela uma formação voltada à militância, que lhe proporcionou senso crítico e analítico sobre a conjuntura política e social que envolve a formação identitária dos movimentos sociais. Nesse processo, a autoeducação de iguais e a autogestão da ordem social reprodutiva não podem ser separadas uma da outra, pois a educação significa o processo de interiorização das condições de legitimidade do sistema que explora o trabalho como mercadoria (MÉSZÁROS, 2008).

As palavras de Samuma retratam a necessidade de se estabelecer uma prioridade em relação à escolarização dos jovens, de modo a contemplar as transformações que os movimentos sociais atravessaram durante sua trajetória. No entanto, para além de uma formação básica, a educação deve ter suas prioridades, neste caso, ensinar o valor da terra e sua importância para a sobrevivência dos seres humanos. Nesse sentido, Samuma diz:

[...] nós negamos os povos indígenas, os conhecimentos dos indígenas um povo que tem 12 mil anos aqui, negamos os conhecimentos dos povos pretos, que veio da África e que tem grande conhecimento, principalmente o povo Banto. Tentamos reverter isso, mais isso é muito difícil porque ela (a negação) está incorporada na alma e na mente das pessoas, então isso é um trabalho desgastante, muito difícil, sair da normalidade. Muitos dos alunos que formaram nos cursos técnico voltaram, pra lecionar, tem poucos, mais muitos voltaram e estão dentro do processo, mas o problema é que a escola, essa escola, ela deforma as pessoas, a gente coloca o filho pra formar e ela deforma, porque como a visão é urbanoide, a concepção é do menino ir pra fora, 
educação exportadora, não é educação integradora, de reafirmar seu local, a sua identidade, então não tem essa filosofia, é de negar os povos originários, é de negar os povos africanos, então é sempre de negação, e no contexto da escola, como já disse, é cartesiana, das caixinhas, então não é escola holística, que pensa o todo, que a agroecologia passa por ai, pela questão holística (Samuma. Marcella Gomez. 10/2019).

De acordo com Zacchi (2016), a identidade da luta se constrói na própria luta e não se limita a uma afirmação do seu caráter nacional, isso porque os movimentos sociais se alinham com grupos ambientais internacionais, defendendo um desenvolvimento sustentável e a conservação do ambiente, contribuem no combate à desigualdade de relação entre homens e mulheres e promovem a aproximação entre "Eu" e as múltiplas variáveis, tanto no tempo quanto no espaço, que compõe a "identidade" destes movimentos".

Durante a narrativa de Cedro, que atualmente auxilia na organização de frentes para a luta dos movimentos junto a órgãos estaduais e municipais do estado da Bahia, os movimentos sociais, principalmente o MST, lutam pela igualdade de gênero, pela representatividade camponesa junto a sociedade e por uma educação emancipatória. Em sua narrativa, apresenta a importância do processo educativo na construção social e política dentro dos assentamentos de reforma agrária:

O MST tem um ponto de direcionamento político em relação a agroecologia, e aquela escola de formação que hoje existe dentro da Terra Vista, é um foco que o MST tirou nas regiões de ter as escolas modelos para desenvolver a agricultura, a agroecologia, então no extremo sul tem uma escola desse formato, aqui no sul tem, no sudoeste tem, na chapada diamantina tem. Essa é uma política interna do MST em relação à implementação de um novo modelo de educação. Cada região importante pro MST tem uma escola modelo, umas evoluíram mais outras menos, entendeu, pela própria articulação da região, isso tem a questão institucional, o governo tem que entrar e apoiar essa estrutura; tanto que no Terra Vista hoje tem uma escola estadual, mais antes não era [...] Tudo foi pesado dentro do movimento dos trabalhadores sem-terra, essa era uma estratégia que o MST tinha em relação à educação, sempre foi, tanto que em outras regiões existem escolas modelos com a mesma proposta entendeu (Cedro. Marcella Gomez. 09/2019).

\footnotetext{
"Aleida Assmann. Espaços da recordação: normas e transformações da memória cultural. As teorias da memória de Nietzsche, Halbwachs ou Nora acentuam o caráter construtivista da recordação, seu caráter segurador da identidade, e afirmam o direito dela em face de uma ciência histórica objetiva e neutra. Nos três casos, a oposição mestra se dá entre habitado e inabitado: a memória "pertence a portadores vivos com perspectivas parciais"; a história, ao contrário, "pertence a todos e a ninguém", é objetiva e, por isso mesmo, neutra em relação à identidade. 2011, p.146.
} 
A narrativa de Cedro sobre a construção de uma perspectiva de mudança frente ao compromisso com a educação e os exemplos apresentados, não se refere ao conteúdo apresentado em relatórios governamentais, mas sim a documentos disponibilizados através de publicações técnicas e científicas realizadas pelo próprio MST em seu site (www.mst.org.br). De acordo com o MST, existem mais de 2 mil escolas públicas construídas em assentamentos, 200 mil crianças, adolescentes, jovens e adultos com acesso gratuito à educação, 50 mil adultos alfabetizados e 2 mil estudantes em cursos técnicos ou de ensino superior.

As memórias destes colaboradores retratam a educação como ponto de partida para qualquer transformação social, política e também cultural. Sem um sistema de educação produtivo não existe luta por terra, por igualdade ou por oportunidade. Os movimentos sociais têm como perspectiva o engajamento, para produzir uma trajetória de vida. Deve-se reconhecer a memória como uma reconstrução continuamente atualizada do passado e não uma reconstrução fiel do mesmo, ou seja, a memória é mais um enquadramento que um conteúdo, um objetivo alcançável, um conjunto de estratégias, de modo a nos dar a noção de que o que passou não está definitivamente inacessível, já que é possível fazê-lo reviver através das lembranças.

Os modos de organização e desenvolvimento dos movimentos sociais esbarram em um denominador comum, a educação. Isso porque acreditam que, através dela, as transformações serão solidificadas, as atitudes compreendidas e a motivação expandida. Para Ipê-roxo, o período em que sua consciência de militância desabrochou foi durante uma de suas experiências no período da adolescente:

Ainda na adolescência, ele (pai) me botou no serviço militar mirim, que eu chamo de serviço militar mirim, que era aquela história de escoteiro e bandeirante. Aí é que eu fui ter contato com a realidade de periferia, essas coisas todas e aquilo me causava um transtorno, chegava no inverno eu não queria vestir roupa de frio pra sentir um pouco do que o povo tava sentindo, mas aí comecei no movimento estudantil, então fui fazendo toda essa caminhada (Ipê-roxo. Marcella Gomez. 09/2019).

Para os colaboradores, a educação é o ponto chave, a base para a transformação, ou seja, a prioridade dos movimentos sociais. Nesse sentido, a agroecologia surge como uma ferramenta de engajamento político, 
fortalecimento social e representatividade cultural, que passa a representar um núcleo específico de motivação pessoal e coletiva, aos que consideram o trabalho na terra um estado de soberania.

A importância da agroecologia para a formação dessas crianças que frequentam essas escolas é tudo, seria o processo, mais você hoje, como eu disse a você, tem as escolas extremamente urbanas que dificulta essa formação, então você já tem a globo, a bandeirante, que incentiva todo mundo - o agro é pop, o agro é tudo - e ao mesmo tempo você tem uma escola que está baseada nessa perspectiva. Qual é o problema disso? O problema é que estamos indo para outra perspectiva humana, desenvolvimento humano, nós estamos com outra perspectiva do acirramento entre o trabalho e o capital, nós estamos indo pra sociedade das tecnologias, da robótica, da nanotecnologia, todos os processos mais sofisticados que a humanidade criou apropriada pelo capital, que necessita ter outro ser, e eles estão transformando outro ser. A agroecologia, a gente tem que entender que não existe sem a terra. Sem a terra, sem o território, não existe a agroecologia; segundo: nós temos que entender que agroecologia é uma ciência que pode nos ajudar a ser contra hegemônico, ou seja, é uma ciência que ajuda a ir para além do capital. A agroecologia não é só pra produzir coisas, não é pra produzir mercadorias, a agroecologia é pra (pausa), é uma ciência que ela é transversal a todos os processos, ela é holística, então nessa parte ela tem forte peso, e o último que eu falei, a educação libertadora pra que a gente possa reconhecer nosso passado, nosso presente e reconstruir nosso futuro, reconstruir não, construir nosso futuro (Samuma. Marcella Gomez. 09/2019).

Como ferramenta para a socialização de conhecimentos empíricos e técnicos, a agroecologia é indispensável no processo de formação daqueles que se engajam na luta pela terra com o ideal de igualdade e empoderamento. Nos assentamentos visitados, é possível verificar que a ideia de uma produção agroecologia é sinônimo de qualidade de vida, segurança alimentar e empoderamento camponês.

Ao definir a agroecologia como a aplicação dos conceitos e princípios ecológicos para desenhar agroecossistemas sustentáveis, Altieri (2012) ultrapassa o simples uso de práticas alternativas e apresenta a possibilidade de desenvolvimento de agroecossistemas menos dependentes de venenos. Para Caporal e Costabeber (2005) a agroecologia necessita de mudanças nos currículos de formação dos profissionais que irão atuar como agentes de desenvolvimento rural, de métodos de pesquisa e extensão rural mais apropriados e requer uma estratégia integradora de conhecimentos, complexa, sistêmica e holística, capaz de aglutinar os conhecimentos científicos e empíricos. 
Sob essa perspectiva, as narrativas expuseram o fato de que existem diferenças de argumentação sobre o que é a agroecologia dentro dos movimentos sociais. Cedro apresenta algumas dessas diferenças, e, de acordo com sua narrativa, cada movimento constrói suas relações sociais e políticas mediante as necessidades que possuem frente ao processo de luta, visibilidade sociopolítica e processo educacional. Para ele:

As questões sobre a conservação dependem da organização de cada movimento, não dá para dizer que é nivelado não, os movimentos têm suas diferenças de organização, mas o sentido é o mesmo em relação a conservação, sustentabilidade, agroecologia, entendeu, da melhoria da qualidade de vida, mas lógico que cada um vai atuar com isso de acordo com sua dinâmica de organização. Em relação a agroecologia o Terra Vista é um padrão para os outros movimentos, tanto que alguns cursos que são ofertados lá, assentados de outros movimentos de outros assentamentos atuam nesse curso, fazem o curso né, estudam, vão participar (Cedro. Marcella Gomez. 09/2019).

A integração entre diferentes conhecimentos para organizar um complexo multidisciplinar e interdisciplinar que emerge dos centros acadêmicos, a partir dos estudos sobre manejo de solos tropicais e produção agroecológica de alimentos da pesquisadora Ana Primavesi ${ }^{12}$, se une ao conhecimento tradicional camponês para transformar a perspectiva de produção implementada pela Revolução Verde de 1960.

Tendo em perspectiva que as memórias mudam de acordo com quem as estabelece, os registros oral e escrito, organizados a partir dos depoimentos, representam um ganho significativo na compreensão da conjuntura política, social, econômica e ambiental, sobre a qual os movimentos sociais da região Sul da Bahia, microrregião Ilhéus-Itabuna, se organizaram e se mantêm. Nesse contexto, a organização e a manutenção desses movimentos sociais no território Litoral Sul da Bahia durante as décadas de 1970 até os anos 2000 têm sido otimizadas mediante a educação. Não obstante, o processo de formação das entrevistadas se assemelha, pois, em algum momento de suas trajetórias, estiveram inclusos no processo de formação para militância adotado pelo MST.

\footnotetext{
${ }^{12}$ Engenheira agrônoma pioneira no mundo em agroecologia formou-se na Áustria, seu país de origem, e mudou-se com seu marido para o Brasil após a Segunda Guerra Mundial. Suas pesquisas apontam para uma agricultura que privilegie a atividade biológica do solo com um alto teor de matéria orgânica, entre suas contribuições para a agronomia está a compreensão do solo como um organismo vivo e com diversos níveis de interação com a planta.
} 


\section{Considerações Finais}

Ao longo do trabalho, organizou-se uma coletânea de memórias sobre o processo de ocupação de terras no Sul da Bahia. Foi possível perceber as motivações pessoais e coletivas dos colaboradores a participar dos enfrentamentos, e compreender como a luta por terras nessa região ressignificou a identidade local.

Essas mesmas memórias foram capazes de apontar (ou identificar) o interesse pelo bem-estar do ambiente, como uma característica intrínseca à formação pessoal de cada sujeito e que a agroecologia é considerada uma ferramenta capaz de otimizar os conhecimentos empíricos, relacionando-os a técnicas mais apropriadas de produção. Organizaram-se informações acerca da agroecologia, de acordo com o entendimento de cada colaborador e alguns deles narraram que a agroecologia é "tudo" para os movimentos sociais, comprometidos em legitimar a função social da terra. A agroecologia passou a ser entendida como o meio para alcançar uma organicidade sociopolítica dentro do próprio movimento.

Lançando mão do emprego de tecnologia e dos conhecimentos tradicionais, a agroecologia se funde aos ideais de luta pela terra, organização política, reforma social, mitigação das crises ambientais e fortalecimento cultural de cada núcleo formado e visitado durante a realização das entrevistas. Não sendo capaz de identificar se para os colaboradores há um entendimento específico sobre a ciência agroecologia, esta pesquisa se propôs a afirmar que eles, através de suas organizações políticas, preocupações com a dignidade e bem-estar social, ressignificação cultural e proteção ambiental já faziam agroecologia sem denominá-la como tal.

Nesse meio tempo, as memórias sobre as ocupações de terras no Sul da Bahia estão vinculadas ao processo de revitalização dessas áreas, que no momento das ocupações estavam devastadas pela "vassoura de bruxa"13. Essas memórias também apresentam a competência, o comprometimento e o vigor de homens e mulheres em promover ações de representatividade social e política capazes de integrar trabalhadores e trabalhadoras rurais à

\footnotetext{
${ }^{13}$ Doença causada por fungo e responsável pela morte dos cacaueiros, o que ocasionou a queda na produção de cacau e a falência de muitos fazendeiros cacauicutores a partir de 1989.
} 
nova realidade, como responsáveis pelo bem-estar, manejo e produção em suas terras, de modo a fortalecê-los e empoderá-los.

Acessar essas memórias a partir da perspectiva de trabalhadores e trabalhadoras rurais permite expandir conhecimentos, desmistificar conceitos e atribuir valores aos esforços de todos e todas que se uniram à luta por terras. Memórias são necessárias para conhecer esse período por meio da narrativa de seus participantes, nossos colaboradores. Desta maneira, tornouse possível identificarmos os porquês dessas lutas, por quem foram realizadas, para que foram organizadas e como se mantêm.

As memórias das ocupações, a importância da agroecologia, a necessidade de fortalecimento dos movimentos e da organização sociopolítica de cada núcleo encaminham à reflexão sobre a importância desses movimentos, e de outros, para a conservação da Mata Atlântica. A migração desses movimentos para o Sul da Bahia, em uma época em que a floresta entrou em colapso devido à "vassoura de bruxa", têm impedido o desflorestamento total do local, conservando assim as áreas naturais e dando a elas um novo significado, pois onde antes se plantavam apenas "pés" de cacau, passou-se a plantar uma série de espécies capazes de regenerar o ambiente, alimentar pessoas e produzir recursos.

Por fim, considerando-se que este estudo pode representar uma nova possibilidade de se entender o processo das lutas por terra na região Sul da Bahia, ouvir a narrativa dos colaboradores contribuiu para que se desenvolvesse uma criticidade mais acurada sobre os contos e relatos já feitos, permitiu a apresentação de memórias silenciadas pelo tempo e pela posição social, contribuiu para o crescimento pessoal da equipe e argumentou que a educação, o emprego de tecnologia e a (re) valorização do conhecimento tradicional contribuem para o desenvolvimento comunitário local.

\section{BIBLIOGRAFIA}

ALTIERI, M. Agroecologia: bases científicas para uma agricultura sustentável. São Paulo, Rio de Janeiro: Expressão Popular. 2012. 400p.

ARAÚJO, M. P. N. E SANTOS, M. S. dos. História, memória e esquecimento: implicações políticas. Revista Crítica de Ciências Sociais, n79, 2007, pp.95111. 
ASSMANN, A. Espaços da Recordação: formas e transformações da memória cultural. Trad. Paulo Soethe. Campinas: Editora da Unicamp. 2011. 453p.

BORGES, J. L. MST: do produtivismo a agroecologia. São Paulo; Goiânia: Terceira Margem; Editora da PUC Goiás. 2010. 176p.

CALDART, R. S. et al. Escola em Movimento no Instituto de Educação Josué de Castro. São Paulo: Expressão Popular, 2013. 448p.

CANAVESI, F.; MOURA, I. F. de e SOUZA C de. Agroecologia nas políticas públicas e promoção da segurança alimentar e nutricional. Revista de Segurança Alimentar e Nutricional, v.23, nºspecial, 2016, pp.1019-1030.

CAPORAL, F. R. e COSTABEBER, J. A. Agroecologia: alguns conceitos e princípios. Brasília: MDA/SAF/DATER-IICA. 2009. Disponível em: www.fca.unesp.br/Agroecologia-Conceitoseprincipios. Acesso: 15/01/2020.

FRANÇOIS, E. As novas relações entre memória e História após a queda do Muro de Berlim. Memória em Rede, v.2, n², 2010, pp.17-29.

HALBWACHS, M. A memória coletiva. Trad. Beatriz Sidou. São Paulo: Centauro, 2003. 224p.

JEAN JEAN, M. La Historia Oral y la narrativa como metodologías para el abordaje del terrorismo de Estado, siglo XX en Argentina. Revista Historia y Memoria, $n^{\circ} 20,2020$, pp.61-95.

JOSSO, M. C. História de vida e projeto: a história de vida como projeto e as "histórias de vida" a serviço de projetos. Educação e Pesquisa, São Paulo, v.25, n.2, p. 11-23, 1999.

LEFF, E. Agroecologia e saber ambiental. Agroecologia e Desenvolvimento Rural Sustentável, v.3, n¹, 2002, pp.36-51.

LOPES, L. Michel Laub: literatura, memória, esquecimento. Estudos linguísticos e literários, $n^{\circ}$ 49, 2014, pp.24-38.

LUNA, A. S. e AGUILAR, M. A. E. La agrobiodiversidad como elemento articulador entre el hogar y el huerto urbano. Memorias del V Congreso Latino Americano de Agroecologia, La Plata, 2015. ISBN 978-950-34-1265-7.

MAYWALD, P G. e JÚNIOR, O. M. Estrutura de áreas protegidas dos assentamentos de reforma agrária no município de Uberlândia-MG, Brasil: um estudo de ecologia de paisagem. Sociedade \& Natureza, v.25, nㄱ, 2013, pp.7590.

MÉSZARÓS, I. A educação para além do capital. $2^{a}$ ed. São Paulo: Boitempo, 2008.

PAIXÃO, C. e FRISSO, G. M. Usos da Memória: as experiências do holocausto e da ditadura no Brasil. Lua Nova, n97, 2016, pp.191-212.

POLLAK, M. Memória, Esquecimento, Silêncio. Estudos Históricos, v.2, n³, 1989, pp.3-15.

PORTELLI, A.O massacre de Civitella Val di Chiana (Toscana, 29 de junho de 1944): Mito e política, luto e senso comum. In: Usos e abusos da história oral. Org. Marieta de M. Ferreira e Janaína Amado. Rio de Janeiro: FGV. 1996. 304p. 
PORTELLI, A. Ensaios sobre História Oral. Trad. Francisco Luiz Cássio e Ricardo Santhiago São Paulo: Letra e Voz, 2010. 264p.

PRIMACK, R. e RODRIGUES, E. Biologia da Conservação. Londrina: Midiograf, 2001. 328p.

RIBEIRO, A L. R. Memória e Identidade: reformas urbanas e arquitetura cemiterial na região cacaueira (1880-1950). Ilhéus: Editus, 2005. 208p.

RODRíGUeZ, O. Y. A. El Pasado: Historia o Memoria. Revista Historia y Memória, n9, 2014, pp.57-87.

SCHEUER, J. M. Agroecologia: cuidando da saúde do planeta - palestra de Leonardo Boff. Revista Nera, ano19, n`31, 2016, pp.:166-179.

SEVILLA-GUZMÁN, E. La agroecologia como estrategia metodológica de Transformación social. Agroecología y Gestión de Ambientes Rurales. 2009. Disponível em: http://agroeco.org/brasil. Acesso: 15/01/2020.

SEVILLA-GÚZMAN, E. A perspectiva sociológica em Agroecologia: uma sistematização de seus métodos e técnicas. Agroecologia e desenvolvimento rural Sustentável, v.3, n¹, 2002, pp.19-28.

WIGG, D. et. al. Semeando Novos Tempos: reforma agrária e agroecologia um diálogo possível e necessário - análise a partir do estudo de caso do PDS Osvaldo de Oliveira no Rio de Janeiro. Retratos e Assentamentos, v.19, $\mathrm{n}^{\circ} 1$, 2016, pp.116-147.

ZACCHI, V. J. A enxada e a caneta: linguagem e cultura na construção da identidade do sem-terra. São Paulo: FAPESP. 2016. 316p. 